\title{
Influential Factors in the Preparation of ${ }^{68}$ Ga-DOTATATE
}

\author{
Ping Fang, Mark S. Jacobson, and Joseph C. Hung \\ Division of Nuclear Medicine, Mayo Clinic, Rochester, Minnesota
}

\begin{abstract}
Acceptable and reproducible radiochemical purity $(\mathrm{RP})$ for ${ }^{68} \mathrm{Ga}$-DOTATATE was difficult to obtain with the NETSPOT kit because the manufacturer instructions lacked details on the heater or needles used. Methods: The drug was prepared in an International Organization for Standardization (ISO) 5 environment. Multiple dry baths and needle types were used to investigate the effects of reaction temperature and metal contamination, respectively. Temperature curves were obtained with a calibrated thermocouple. The influence of the accuracy of the NETSPOT reagent volume and its effect on outcome were investigated. Results: The AccuBlock dry bath required recalibration for the ISO 5 environment; after calibration, the temperature was stable (only $\pm 0.1^{\circ} \mathrm{C}$ from the set point). When we followed package insert recommendations (dry bath temperature set to $98^{\circ} \mathrm{C}$, reaction time of $8 \mathrm{~min}$ ), the reaction temperature was $90.6^{\circ} \mathrm{C}$. When Becton Dickinson needles were used for reconstitution, 15 of 18 runs (83\%) did not meet the RP specification. However, B. Braun Medical needles achieved satisfactory and stable RP. When the ${ }^{68} \mathrm{Ga}$ generator was eluted with $5.0 \mathrm{~mL}$ of $0.1 \mathrm{M}$ hydrochloric acid $(\mathrm{HCl})$, only $3.8-3.9 \mathrm{~mL}$ of eluate reached the reaction vial; this volume did not impact labeling (final $\mathrm{pH}$ was 3.8). The labeling success rate increased markedly if the ${ }^{68} \mathrm{Ga}$ eluate was passed through a conditioned silica gel cartridge or if no cartridge was used; then, RP was more than $99 \%$. $\mathrm{HCl}$ contact with the septum of the labeling vial reduced RP. Conclusion: The needle type and the temperature setting of the dry bath have critical roles in ${ }^{68} \mathrm{Ga}$-DOTATATE preparation. The AccuBlock dry bath has excellent stability and accuracy and can be used for reliable preparation. By using a conditioned silica gel cartridge or by eliminating the cartridge altogether, the RP is reliably high and stable.
\end{abstract}

Key Words: ${ }^{68} \mathrm{Ga}-\mathrm{DOTATATE} ;{ }^{68} \mathrm{Ge}$ breakthrough; NETSPOT; neuroendocrine tumors; PET; preparation

J Nucl Med Technol 2020; 48:263-268

DOI: $10.2967 /$ jnmt.119.241224

$\mathbf{N}$ euroendocrine tumors have receptors for somatostatin, a hormone that regulates the endocrine system. A somatostatin receptor imaging agent was approved in 2016 by the U.S. Food and Drug Administration (U.S. FDA) for PET

Received Dec. 20, 2019; revision accepted Feb. 26, 2020.

For correspondence contact: Ping Fang, Division of Nuclear Medicine, Mayo Clinic, 200 First St. S.W., Rochester, MN 55905.

E-mail: fang.ping@mayo.edu

Published online Apr. 10, 2020.

COPYRIGHT (c) 2020 by the Society of Nuclear Medicine and Molecular Imaging. imaging of neuroendocrine tumors in adult and pediatric patients (1). The imaging agent ${ }^{68} \mathrm{Ga}$-DOTATATE is a radioconjugate consisting of the somatostatin analog tyrosine-3-octreotate labeled with the tracer ${ }^{68} \mathrm{Ga}$ via the macrocyclic chelating agent dodecanetetraacetic acid. In terms of convenience in patient care, ${ }^{68} \mathrm{Ga}$-DOTATATE represents a major advantage because imaging can be completed in less than $2 \mathrm{~h}$; in comparison, an octreotide scan requires $2 \mathrm{~d}(2)$.

In our initial experience preparing ${ }^{68} \mathrm{Ga}$-DOTATATE following the manufacturer instructions, we encountered numerous problems that resulted in low radiochemical purity (RP) and low rates of successful preparation. Notably, the instructions did not specify a temperature for the reaction solution, nor did they specify manufacturer or model names for the dry bath or sterile needles. To establish a reliable, high-quality production method, we evaluated the effects of 3 reaction conditions. The first was the dry-bath temperature and the actual temperature of the reaction solution, the second was metal contamination from needles, and the third was the accuracy of the NETSPOT reagent volume and the effect of volume on outcome. In this study, we aimed to systematically evaluate factors that affect preparation of ${ }^{68} \mathrm{Ga}$-DOTATATE and establish guidelines that would increase the rate of successful preparations for new users.

\section{MATERIALS AND METHODS}

${ }^{68} \mathrm{Ga}$-DOTATATE was prepared with a GalliaPharm ${ }^{68} \mathrm{Ge} /{ }^{68} \mathrm{Ga}$ generator (Eckert and Ziegler Radiopharma), sterile ultrapure $0.1 \mathrm{M}$ hydrochloric acid $(\mathrm{HCl})$, and the NETSPOT kit (Advanced Accelerator Applications). We followed the NETSPOT manufacturer instructions (3) and prepared ${ }^{68} \mathrm{Ga}$-DOTATATE in an aseptic International Organization for Standardization (ISO) 5 isolator with laminar flow. Briefly, we used $5.0 \mathrm{~mL}$ of $0.1 \mathrm{M} \mathrm{HCl}$ to elute ${ }^{68} \mathrm{GaCl}_{3}$ from the ${ }^{68} \mathrm{Ge} /{ }^{68} \mathrm{Ga}$ generator, and for some preparations, the eluate was passed through a silica gel cartridge. The cartridge was connected to a sterile, siliconized needle plus a sterile filter and then connected to the reaction vial of the NETSPOT kit. With a vent filter (Millipore Millex-FG) and needles (B. Braun Medical 100 Sterican $[0.60 \times 60 \mathrm{~mm}]$ or Becton Dickinson Precisionglide hypodermic [siliconized] $[0.6 \times 60 \mathrm{~mm}]$ ), this elution procedure took $2.5 \mathrm{~min}$. Within $10 \mathrm{~min}$ of adding ${ }^{68} \mathrm{GaCl}_{3}$ to the reaction vial, $0.5 \mathrm{~mL}$ of reaction buffer was injected and the vial was heated in a dry bath (set-point range, $95^{\circ} \mathrm{C}-98^{\circ} \mathrm{C}$ ). The instructions indicated heating for at least $7 \mathrm{~min}$ but no longer than $10 \mathrm{~min}$. 


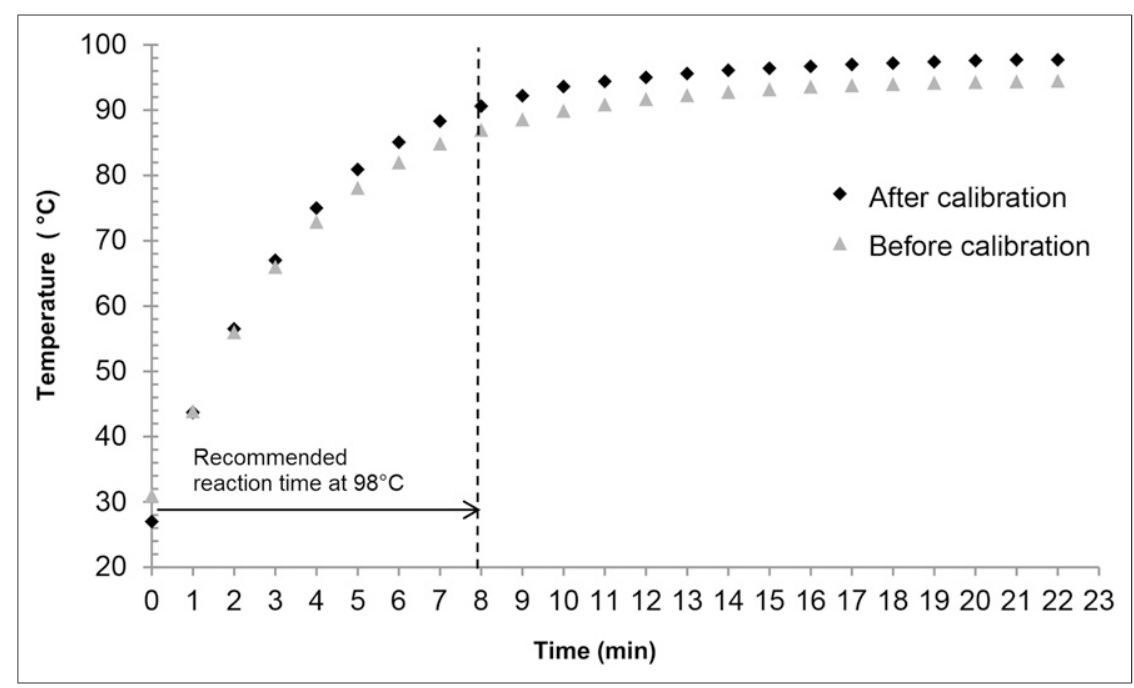

FIGURE 1. Temperature difference before and after calibration at $98^{\circ} \mathrm{C}$. Reaction vials containing $5.0 \mathrm{~mL}$ of water were heated in AccuBlock D1200 dry bath. Before calibration, measured temperature was $3.5^{\circ} \mathrm{C}$ below set point of $98^{\circ} \mathrm{C}$; after calibration, measured temperature reflected set temperature. Dotted line is parameter of selected working condition: $98^{\circ} \mathrm{C}$ set point and heating for $8 \mathrm{~min}$. used for ${ }^{68} \mathrm{Ge}$ breakthrough testing) were analyzed using inductively coupled plasma mass spectrometry.

\section{Cartridge Conditions and Volume and $\mathrm{pH}$ of the Final Product}

We tested several cartridge conditions: unconditioned silica gel, silica gel conditioned with $0.1 \mathrm{M} \mathrm{HCl}(2.0 \mathrm{~mL})$, and silica gel conditioned with water $(2.0 \mathrm{~mL})$ followed by $5.0 \mathrm{~mL}$ of air. We additionally assessed the preparation when no cartridge was used.

We used $5.0 \mathrm{~mL}$ of $0.1 \mathrm{M} \mathrm{HCl}$ to elute the generator. Depending on the cartridge condition, different volumes of $\mathrm{GaCl}_{3}$ solution were eluted into the reaction vial. The reaction $\mathrm{pH}$ was measured with $\mathrm{pH}$ test paper (Advatec BPB, pH 2.8-4.4).

\section{Endotoxin Test}

Endotoxin testing was conducted using the Endosafe multiple-cartridge system (Charles River).
RP was determined with thin-layer chromatography. Glass microfiber chromatography paper impregnated with silica gel (Agilent Technologies, Inc.) was used for the stationary phase, and $1 \mathrm{M}$ ammonium acetate:methanol $(1: 1 \mathrm{v} / \mathrm{v})$ was used for the mobile phase. According to the revised NETSPOT package insert (4), ${ }^{68} \mathrm{Ga}$ DOTATATE RP should be at least $95 \%$ and other ${ }^{68} \mathrm{Ga}$ species should be no more than $5 \%$. The success rate was defined as the percentage of production runs that met the minimal RP.

\section{Temperature Control}

Temperature curves were obtained using NETSPOT reaction vials containing $5.0 \mathrm{~mL}$ of water and dry baths set to $95^{\circ} \mathrm{C}$ and $98^{\circ} \mathrm{C}$. Temperatures were verified with a calibrated thermocouple thermometer (Fluke 542 II B). We tested 2 dry heaters: HotPot (Capintec, Inc) and AccuBlock D1200 (Labnet International, Inc.). Plastic covers were used to reduce heat loss and stabilize the temperature in the ISO 5 environment.

\section{${ }^{68} \mathrm{Ge}$ Breakthrough and Metal Content}

We measured eluate samples from the ${ }^{68} \mathrm{Ge} /{ }^{68} \mathrm{Ga}$ generator weekly to assess ${ }^{68} \mathrm{Ge}$ breakthrough and metal content. Samples were obtained after the generator had not been eluted for more than $48 \mathrm{~h}$, and eluates were not passed through a silica cartridge. The breakthrough analysis was performed by an approved outside vendor on a decayed sample of the drug product. Briefly, the numbers of $\gamma$-rays were measured for a specific time as a function of energy (of each $\gamma$-ray). A series of calibration procedures then reduced the $\gamma$-events to a quantitative measurement of sample activity. Eluates from 2 generators were fully tested with $\gamma$-spectrum analysis to verify that ${ }^{68} \mathrm{Ge}$ breakthrough was within specified limits $(<0.00100 \%)$.

Zinc and iron ions compete with $\mathrm{Ga}^{3+}$ in the labeling reaction and can cause reaction failure. We evaluated the influence of metal contaminants from Becton Dickinson needles and from B. Braun needles. Zinc and iron ion samples (the same as those

\section{RESULTS}

\section{Temperature Control}

The ISO 5 isolator is an environment with a high laminar airflow. Because the airflow is very strong (1,000 air changes per hour), it can affect heat exchange and heat loss with dry baths, particularly at higher temperatures, resulting in temperature deviations from the set point. We assessed the temperature deviation and temperature

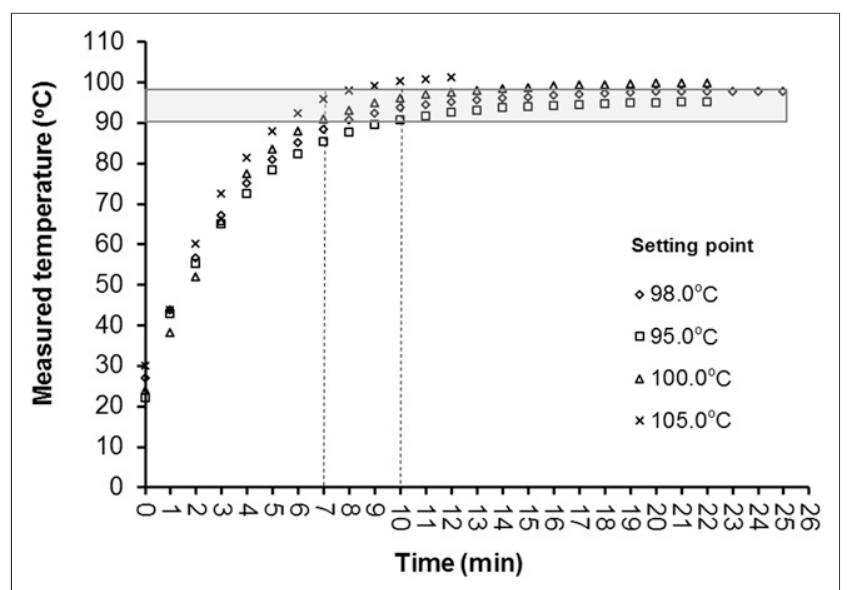

FIGURE 2. Temperature curves for selection of dry bath set points. Temperatures were measured in reaction vials containing $5.0 \mathrm{~mL}$ of water. Box denotes manufacturer-recommended range of temperatures for labeling in reaction solution $\left(90^{\circ} \mathrm{C}-98^{\circ} \mathrm{C}\right)$. Principal investigator recommended heating time of 7-10 min at $95^{\circ} \mathrm{C}-98^{\circ} \mathrm{C}$ set point. Temperature at intersection of box and 2 dotted lines will be best range for labeling. For $105^{\circ} \mathrm{C}$ set point, temperature will easily reach at least $98^{\circ} \mathrm{C}$ at $8 \mathrm{~min}$. Both $98^{\circ} \mathrm{C}$ and $100^{\circ} \mathrm{C}$ set points fit well within range of $8-10 \mathrm{~min}$. At $7 \mathrm{~min}$ and $98^{\circ} \mathrm{C}$ set point, temperature will be below $90^{\circ} \mathrm{C}$. For $95^{\circ} \mathrm{C}$ set point, temperature can reach only $90^{\circ} \mathrm{C}$ at $10 \mathrm{~min}$. 


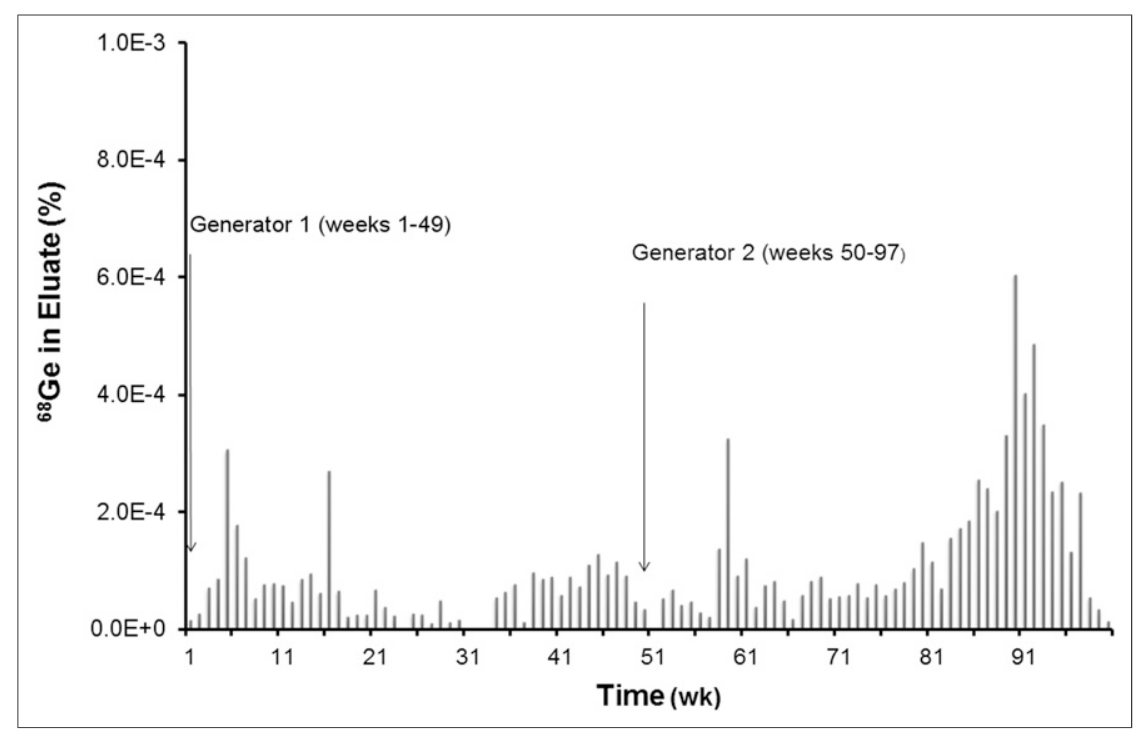

FIGURE 3. ${ }^{68} \mathrm{Ge}$ content in generator eluates. Generators were eluted weekly; specification was $<0.00100 \%$. Generator 1 was eluted about 480 times in $375 \mathrm{~d}$, and ${ }^{68} \mathrm{Ge}$ breakthrough was $<0.00031 \%$ throughout. Generator 2 was eluted about 720 times in $339 \mathrm{~d} ;{ }^{68} \mathrm{Ge}$ breakthrough increased to up to $0.00060 \%$ after 590 elutions (280 d) but was still within $0.00100 \%$ limit.

changes using a NETSPOT reaction vial containing $5.0 \mathrm{~mL}$ of water. The AccuBlock dry bath had a highly stable temperature, with only a $\pm 0.1^{\circ} \mathrm{C}$ deviation from the set point. In contrast, the HotPot showed variations of $\pm 3.0^{\circ} \mathrm{C}$ from the set point. Given the superior temperature stability of the AccuBlock, the remaining assessments were performed with the AccuBlock only. Routine production also was conducted only with the AccuBlock.

The AccuBlock was factory-calibrated at $40^{\circ} \mathrm{C}$. At a $98^{\circ} \mathrm{C}$ set point, the actual temperature was $94.5^{\circ} \mathrm{C}$ (i.e., deviated by $-3.5^{\circ} \mathrm{C}$ ). After recalibration, the dry bath set at $98^{\circ} \mathrm{C}$ had deviations of $\pm 0.1^{\circ} \mathrm{C}$, and a temperature curve showed that the water in the vial reached the set-point temperature after approximately $21-22 \mathrm{~min}$ (Fig. 1).

A representative of the manufacturer indicated that the reaction temperature should range from $90^{\circ} \mathrm{C}$ to $98^{\circ} \mathrm{C}$ (pharmacist [operations manager], Advanced Accelerator Applications, oral communication, November 2016); the representative did not indicate an optimal temperature. We set the dry bath to temperatures from $95^{\circ} \mathrm{C}$ to $105^{\circ} \mathrm{C}$ and ensured that the set-point temperature was attained before a reaction vial was placed. We then measured how much time was needed for the temperature of the water in the reaction vial to exceed $90^{\circ} \mathrm{C}$ (range, 6$8 \mathrm{~min}$ ) (Fig. 2). The water temperature after $8 \mathrm{~min}$ ranged from $87.8^{\circ} \mathrm{C}$ to $97.9^{\circ} \mathrm{C}$ for set points ranging from $95^{\circ} \mathrm{C}$ to $105^{\circ} \mathrm{C}$ (Fig. 2).

For routine preparation of ${ }^{68} \mathrm{Ga}$-DOTATATE, the dry bath was set to $98^{\circ} \mathrm{C}$ and the reaction vial was heated for $8 \mathrm{~min}$. We selected these parameters because $98^{\circ} \mathrm{C}$ was the highest temperature recommended by the manufacturer and the water temperature in the reaction vial was still less than $90^{\circ} \mathrm{C}$ after a $7-\mathrm{min}$ incubation.

\section{${ }^{68} \mathrm{Ge}$ Breakthrough}

The first generator was eluted about 480 times in $375 \mathrm{~d}$, and the ${ }^{68} \mathrm{Ge}$ breakthrough was less than $0.00031 \%$ throughout. The second generator was eluted about 720 times in $339 \mathrm{~d}$; the ${ }^{68} \mathrm{Ge}$ breakthrough increased to $0.00060 \%$ after 590 elutions ( $280 \mathrm{~d})$, but it was still within the $0.00100 \%$ limit (Fig. 3) (5).

\section{Metal Content}

Metal contamination can compete with ${ }^{68} \mathrm{Ga}$ for the chelator group. Thus, the weekly samples also were tested for iron and zinc content (Fig. 4). During the first $2 \mathrm{mo},{ }^{68} \mathrm{Ga}$ eluates were taken from the first generator with a Becton Dickinson needle and collected in a glass vial with a rubber stopper. However, we realized that glass and rubber could cause high iron and zinc contamination; subsequently, B. Braun needles and metal-free plastic tubes were used for sample collection. We also tested $0.1 \mathrm{M} \mathrm{HCl}$ acid passed through a Becton Dickinson needle or a B. Braun needle and $0.1 \mathrm{M} \mathrm{HCl}$ solution that was in contact with the rubber septum of a NETSPOT reaction vial (Table 1). The zinc content of acid that had contacted the vial septum was up to 598 -fold higher than that of the normal eluate (4.83 vs. $2,887.13 \mathrm{ng} / \mathrm{mL}$ ); iron content also was 11-fold higher (6.00 vs. $66.23 \mathrm{ng} / \mathrm{mL}$ ).

\section{Cartridge Conditions}

For 33 preparations, the silica cartridge was conditioned with $2.0 \mathrm{~mL}$ of $0.1 \mathrm{M} \mathrm{HCl}$ and yielded a mean RP of $99.58 \%$ (SD, $0.27 \%$ ) and a success rate of $100 \%$. For

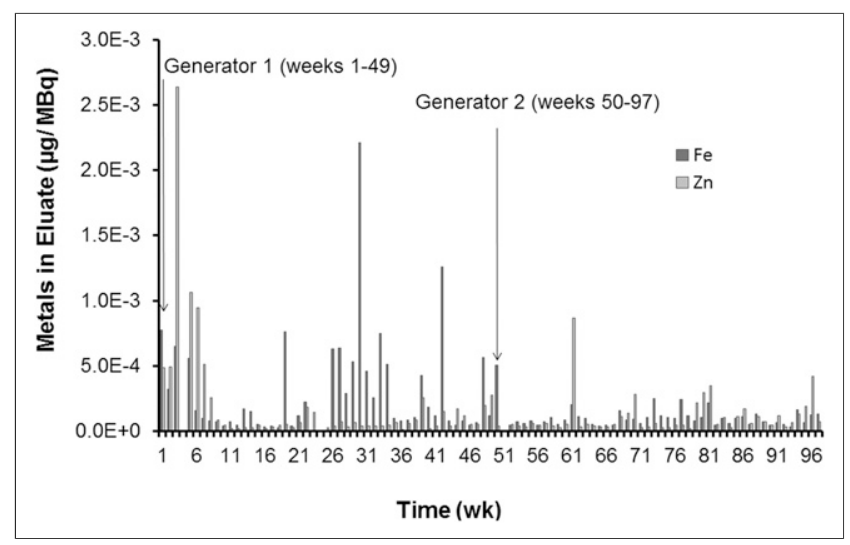

FIGURE 4. Comparison of iron and zinc content of eluates. Weekly eluates were obtained from 2 generators (specification was $<0.01 \mu \mathrm{g} / \mathrm{MBq}$ ). Data showed that both iron and zinc content were well below specifications. 
TABLE 1

Comparison of Iron and Zinc Content in $0.1 \mathrm{M} \mathrm{HCl}$ after Contact with Potential Sources of Contamination

\begin{tabular}{ccc}
\hline $\begin{array}{c}\text { Contamination } \\
\text { source }\end{array}$ & $\begin{array}{c}\text { Iron } \\
(\mathrm{ng} / \mathrm{mL})\end{array}$ & $\begin{array}{c}\text { Zinc } \\
(\mathrm{ng} / \mathrm{mL})\end{array}$ \\
\hline $\begin{array}{c}\text { Becton Dickinson } \\
\text { needle }\end{array}$ & $84.33 \pm 68.97$ & $4.03 \pm 0.68$ \\
B. Braun needle & $2.27 \pm 2.09$ & $4.56 \pm 2.26$ \\
Contact septa & $66.23 \pm 12.07$ & $2887.13 \pm 278.07$ \\
Gallium eluent & $6.00 \pm 1.41$ & $4.83 \pm 1.92$ \\
without needle & & \\
\hline
\end{tabular}

271 preparations, cartridges were flushed with $2 \mathrm{~mL}$ of sterile water and dried with $5 \mathrm{~mL}$ of air; these preparations yielded a mean RP of $99.08 \%$ (SD, 2.58\%) and a success rate of $97.79 \%$. We noted only 6 failures in the preparation of ${ }^{68} \mathrm{Ga}$-DOTATATE that used conditioned cartridges; of these, 4 were operator-related failures. The mean $\mathrm{RP}$ for all conditioned cartridges $(\mathrm{HCl}$ and water) was $99.13 \%$, and the success rate was $98.03 \%$ (298/304). For the 476 preparations using dry cartridges (without conditioning), the mean RP was $97.18 \%$ (SD, 5.42\%) (this RP was $\sim 2.0 \%$ lower than that for conditioned cartridges), and the success rate was $93.07 \%$ (Table 2). We suspect that an unconditioned cartridge may cause a labeling problem.

The 2019 version of the manufacturer instructions indicated that ${ }^{68} \mathrm{Ga}$ eluates could be obtained without using a silica gel cartridge (4). Weekly analysis of ${ }^{68} \mathrm{Ge}$ breakthrough showed levels well below the specific value of $0.00100 \%$. Without the cartridge, the labeling process was more reliable. The setup procedure also was shortened (fewer steps), and elimination of the cartridge when eluting from the ${ }^{68} \mathrm{Ga}$ generator further improved the RP (mean, $99.37 \%$ [SD, $1.45 \%]$ ) and success rate $(99.11 \%)$ compared with conditioned cartridges. Furthermore, without the cartridge, the final production volume was $5.5 \mathrm{~mL}$, and the $\mathrm{pH}$ was within the acceptable range. The increased success rate also improved patient service (e.g., fewer treatment delays, greater patient volume).

\section{Volume and pH of Final Product}

The manufacturer instructions did not indicate the optimal final product volume. We used a syringe without natural rubber latex to measure $5.0 \mathrm{~mL}$ of $0.1 \mathrm{M} \mathrm{HCl}$ and applied that to elute the ${ }^{68} \mathrm{Ga}$ generator. Of the initial $5.0-\mathrm{mL}$ volume, only $3.8-3.9 \mathrm{~mL}$ of ${ }^{68} \mathrm{GaCl}_{3}$ reached the reaction vial because a porous silica cartridge was used to trap the breakthrough ${ }^{68} \mathrm{Ge}$ and a filter was used to sterilize the eluent. Thus, the silica cartridge retained about $1.1 \mathrm{~mL}$ of eluent. We added $0.5 \mathrm{~mL}$ of buffer to the reaction vial before heating, which made the final volume of the ${ }^{68} \mathrm{Ga}$-DOTATATE injection approximately $4.4 \mathrm{~mL}$ and the $\mathrm{pH} 3.6-3.8$. If a conditioned silica gel cartridge was used, only $4.5-4.6 \mathrm{~mL}$ of eluent reached the reaction vial; with $0.5 \mathrm{~mL}$ of buffer, the final volume was approximately $5.1 \mathrm{~mL}$ and the $\mathrm{pH} 3.6$. If no cartridge was used, then all $5.0 \mathrm{~mL}$ of eluent were in the vial; with $0.5 \mathrm{~mL}$ of buffer, the final volume was $5.5 \mathrm{~mL}$ and the $\mathrm{pH} 3.4$. The acceptable $\mathrm{pH}$ range for the reaction is 3.2-3.8. The differences in final volume affected only the $\mathrm{pH}$ and did not influence the labeling yield or RP.

Figure 5 shows the RPs of different lots of NETSPOT kits. The mean RP was $97.18 \%$, and the success rate was $94.40 \%$ for the 250 preparations before lot PG1917017 was put into use. For lot PG1917017, the mean RP was 99.11\% and the success rate was $96.43 \%$ (54/56). After the next lot, PG1917023, was put into use. Before conditioned cartridges were used in the reconstruction, the mean RP was $96.54 \%$ and the success rate was $95.03 \%(153 / 161)$. When conditioned cartridges were used, the RP was 99.40\% and the success rate was $99.33 \%$ (298/300). When ${ }^{68} \mathrm{Ga}$-DOTATATE was reconstituted without a cartridge, the average RP was $99.37 \%$ and the success rate of $99.11 \%(222 / 224)$ was the highest among all tested conditions.

\section{Endotoxin Test}

The ${ }^{68} \mathrm{Ga}$-DOTATATE solution inhibited the endotoxinspike sample test when the solution was diluted 1:100. However, when the sample was diluted 1:400, the solution did not show inhibition.

\section{DISCUSSION}

The manufacturer-recommended reaction temperature for ${ }^{68} \mathrm{Ga}$-DOTATATE labeling should be between $90^{\circ} \mathrm{C}$ and $98^{\circ} \mathrm{C}$. If the temperature of the heater and the heating time of the reaction vial are maintained within the appropriate range, the success rate for production will be higher (more reliable). Because different working environments will affect the temperature differently, we recommend

TABLE 2

Comparison of Success Rates, Stratified by Cartridge Conditions

\begin{tabular}{lccccc}
\hline & & \multicolumn{3}{c}{ Failure rate } & \\
\cline { 3 - 4 } \multicolumn{1}{c}{ Condition } & Total runs $(n)$ & Total $(n)$ & Due to operator error $(n)$ & Success rate $(n)$ & Mean RP \\
\hline No conditioning & 476 & 33 & 4 & $443(93.07 \%)$ & $97.18 \%(\mathrm{SD}, 5.42)$ \\
$0.1 \mathrm{M} \mathrm{HCl}, 2.0 \mathrm{~mL}$ & 33 & 0 & 0 & $33(100.00 \%)$ & $99.58 \%(\mathrm{SD}, 0.27)$ \\
Sterile water, $2.0 \mathrm{~mL}$ & 271 & 6 & 4 & $265(97.79 \%)$ & $99.08 \%(\mathrm{SD}, 2.58)$ \\
No cartridge & 224 & 2 & 0 & $222(99.11 \%)$ & $99.37 \%(\mathrm{SD}, 1.45)$ \\
Total & 1,004 & 41 & 8 & $963(95.92 \%)$ & $98.25 \%(\mathrm{SD}, 4.19)$ \\
\hline
\end{tabular}




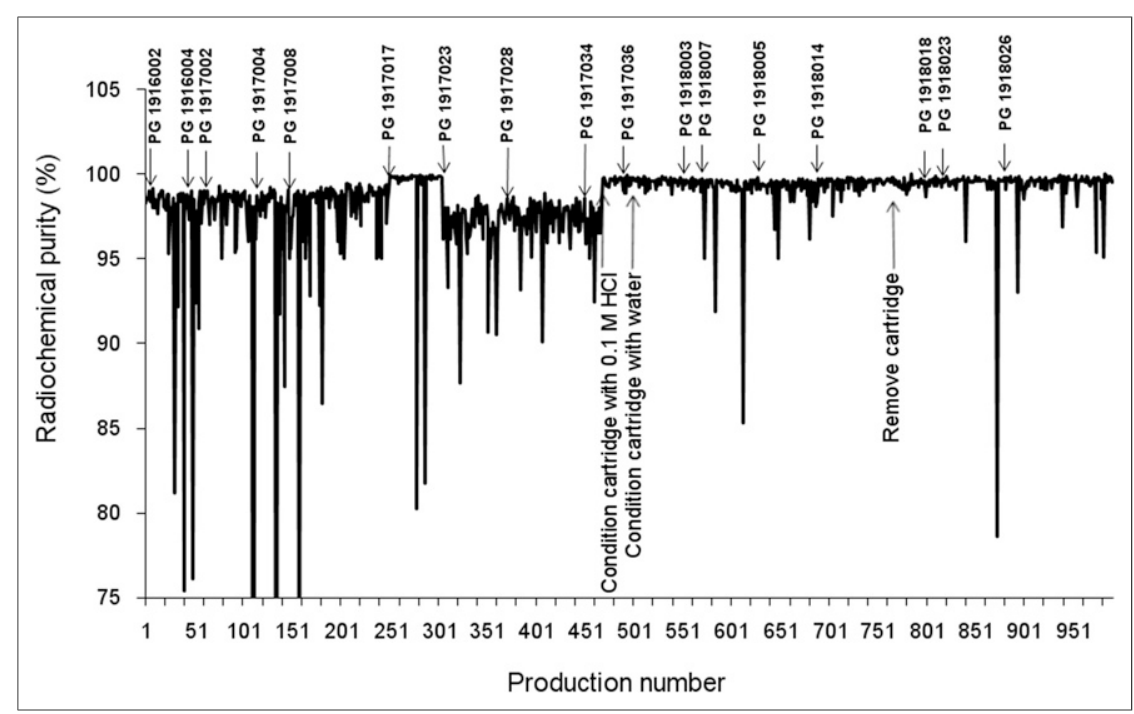

FIGURE 5. RP with multiple lots of NETSPOT kits. Production failures attributable to human error are not shown. Arrows indicate when new lot or cartridge condition was introduced into production. First 476 runs used dry silica gel cartridges to remove ${ }^{68} \mathrm{Ge}$ breakthrough; average RPs were $97.2 \%$ and had more failures, but only 1 lot (PG 1917017) exhibited very high RP and few failures. Remaining run data showed no differences in RPs between conditioned cartridges and no cartridge; both methods were reliable, and average RPs exceeded $99.4 \%$.

recalibrating the heater in the appropriate environment. For heater set points of $95^{\circ} \mathrm{C}$ and $98^{\circ} \mathrm{C}$, the reaction temperatures after incubating for $8 \mathrm{~min}$ were $87.7^{\circ} \mathrm{C}$ and $90.6^{\circ} \mathrm{C}$, respectively. For routine preparations, we used a $98^{\circ} \mathrm{C}$ set point and heated the reaction vial for $8 \mathrm{~min}$.

To assess the impact of metals, we analyzed only the iron and zinc levels from ${ }^{68} \mathrm{Ge} /{ }^{68} \mathrm{Ga}$ generator eluates obtained with Becton Dickinson or B. Braun needles. Iron levels were more than 50-fold higher with Becton Dickinson needles than with B. Braun needles, but zinc levels were similar for both needle types. When Becton Dickinson needles were used, the labeling success rate was only $16.7 \%$ (15/18 production runs did not meet the RP specification). However, B. Braun needles consistently achieved sufficient RP. Although both needle types are made of the same type of stainless steel (304 grade) and protected by a siliconized layer, the B. Braun needles had superior performance. We suspect that the internal and external surfaces of the Becton Dickinson needle are not fully siliconized and that, consequently, metals may be leaching from the unprotected surfaces and competitively interfering with ${ }^{68} \mathrm{Ga}$ labeling. We also assessed a $0.1 \mathrm{M} \mathrm{HCl}$ solution that was in contact with the rubber septum of the NETSPOT reaction vial and noted high iron and zinc levels. We believe that $\mathrm{HCl}$ caused zinc stearate (a common constituent of rubberized septa) to leach into the reaction solution. It is possible that other metal contaminants were present that could affect labeling, but their levels were not measured. We note that $\mathrm{Cu}^{2+}$, if present, also may be competing with $\mathrm{Ga}^{3+}$ at $95^{\circ} \mathrm{C}(6)$.

One specific lot of NETSPOT kits (lot PG1917017, obtained August 2017) had a notably high and consistent
$\mathrm{RP}(>99.6 \%)$. We asked a manufacturer representative whether any changes had been made to the kits, and the representative indicated that the only change was a new lot of silica gel cartridges. The production had an even higher yield when the cartridge was conditioned with $0.1 \mathrm{M} \mathrm{HCl}$ or water. However, the effect of the silica gel cartridge on the labeling reaction remains unclear. In August 2018, the U.S. FDA approved a change in how ${ }^{68} \mathrm{Ga}-$ DOTATATE was synthesized with the NETSPOT kit, by allowing removal of the silica gel cartridge during ${ }^{68} \mathrm{Ga}$ generator elution. The average RP without a cartridge exceeded $99.0 \%$. The weekly elution without silica gel cartridges (Fig. 3, generator 2) was closely monitored for ${ }^{68} \mathrm{Ge}$ breakthrough. After 590 elutions, ${ }^{68} \mathrm{Ge}$ breakthrough had increased to up to two thirds of the allowable limit; in that setting, the silica cartridge does have a role as a safety net. We acknowledge that the generator manufacturer recommends no more than 400 elutions per generator (with $5.0 \mathrm{~mL}$ of $0.1 \mathrm{M} \mathrm{HCl}$ per elution). However, because of a global shortage of ${ }^{68} \mathrm{Ga}$ generators, we eluted the generator more than 400 times and monitored ${ }^{68} \mathrm{Ge}$ breakthrough.

\section{CONCLUSION}

The B. Braun needle and the reaction temperature have critical roles in ${ }^{68} \mathrm{Ga}$-DOTATATE preparation. The internal and external surfaces of the Becton Dickinson needle likely are not fully siliconized, and we surmise that metals leaching from the unprotected surfaces competitively interfere with ${ }^{68} \mathrm{Ga}$ labeling. During our investigations, we also discovered that contact of $0.1 \mathrm{M} \mathrm{HCl}$ with the septum of the reaction vial also reduces RP, likely because zinc stearate is leached from the rubberized septa by $\mathrm{HCl}$. The AccuBlock dry bath, plus a cover, has superior stability and an accurate temperature when placed in a high-air-flow isolator. Elimination of the silica cartridge or use of a conditioned cartridge when preparing ${ }^{68} \mathrm{Ga}$-DOTATATE can markedly increase the RP and production reliability.

"Do" list:

- Do use the AccuBlock or Labnet dry bath.

- Do recalibrate the dry bath at the high temperature setting and in a high-air-flow environment.

- Do use the B. Braun 100 Sterican $0.60 \times 60 \mathrm{~mm} \mathrm{23-}$ gauge $\times 2 \frac{3}{8}$-in needles for the preparation.

"Do-not-do" list:

- Do not allow the liquid in the reaction vial to contact the septa before it is heated. 
- Do not use the Becton Dickinson needles for the preparation.

\section{DISCLOSURE}

Advanced Accelerator Applications supplied researchuse NETSPOT kits. Mayo Clinic does not endorse the products mentioned in this article. No other potential conflict of interest relevant to this article was reported.

\section{ACKNOWLEDGMENT}

We thank Advanced Accelerator Applications for providing expert advice. Portions of this article were published in abstract form ( $\mathrm{J} \mathrm{Nucl} \mathrm{Med.} \mathrm{2017;58[suppl} \mathrm{1]:684)} \mathrm{and}$ presented at the annual meeting of the Society of Nuclear
Medicine and Molecular Imaging, Denver, Colorado, June 10-14, 2017.

\section{REFERENCES}

1. Haug AR, Cindea-Drimus R, Auernhammer CJ, et al. Neuroendocrine tumor recurrence: diagnosis with ${ }^{68}$ Ga-DOTATATE PET/CT. Radiology. 2014;270:517-525.

2. Deppen SA, Blume J, Bobbey AJ, et al. ${ }^{68}$ Ga-DOTATATE compared with ${ }^{111}$ InDTPA-octreotide and conventional imaging for pulmonary and gastroenteropancreatic neuroendocrine tumors: a systematic review and meta-analysis. $\mathrm{J} \mathrm{Nucl}$ Med. 2016;57:872-878.

3. NETSPOT [package insert]. Saint-Genis-Pouilly, France: Advanced Accelerator Applications USA, Inc.; 2017.

4. NETSPOT [package insert]. Saint-Genis-Pouilly, France: Advanced Accelerator Applications USA, Inc.; March 2019.

5. Gallium $\left({ }^{68} \mathrm{Ga}\right)$ chloride solution for radiolabelling. In: European Pharmacopeia. Strasbourg, France: Council of Europe; 2016:1148-1150.

6. Oehlke E, Le VS, Lengkeek N, et al. Influence of metal ions on the ${ }^{68} \mathrm{Ga}$-labeling of DOTATATE. Appl Radiat Isot. 2013;82:232-238. 